\title{
STREPSIPTERA BRASILEIROS. IV. REVISÃO E REDESCRIÇÃO DO GÊNERO BRASIXENOS KOGAN \& OLIVEIRA, 1966 (STYLOPIDAE)
}

RESUMO. Brasixenos Kogan \& Oliveira, 1966 (Strepsiptera, Stylopidae) é revisto; sete espécies são redescritas e é descrita como nova B. myrapetrus (localidade-tipo: Brasil, São Paulo, em Polybia (Myrapetra) paulista - Vespidae).

ABSTRACT. Brasixenos Kogan \& Oliveira, 1966 (Strepsiptera, Stylopidae) is revised; seven species are redescribed, and one, B. myrapetrus, is proposed as new (type-locality): Brazil, São Paulo, in Polybia (Myrapetra) paulista - Vespidae).

\section{INTRODUÇÃO}

O gênero Brasixenos foi criado por Kogan \& Oliveira, em 1966, para agrupar os estrepsípteros que parasitam vespas da subfamflia Polybiinae (Vespidae, Hymenoptera). Foram incluídas no gênero, por ocasião do estabelecimento, seis espécies descritas por aqueles autores, e mais uma descrita anteriormente sob a denominação de Xenos araujoi Oliveira \& Kogan, 1962 e parasita de Apoica paliens (Fabricius, 1804).

Em 1971, Kinzelbach propôs uma nova combinação para o gênero Xenos Rossius, 1793, no qual incluiu os gêneros Clypoxenos Brethes, 1922, Belonogastechthrus Pierce, 1911 e Brasixenos, ao nivel de subgêneros. Brasixenos neste trabalho é novamente tratado ao nível de gênero.

\section{MATERIAL E MÉTODOS}

O material examinado pertence à Coleção $\mathrm{FIOC}$, Fundação Instituto Oswaldo Cruz, Rio de Janeiro (RJ), e à Coleção FAGR, Faculdade de Agronomia, Universidade Federal do Rio Grande do Sul, Porto Alegre (RS).

Faculdade de Zootennia, Veterinária e Agronomia, Pontiffcia Universidade Católica do Rio Grande do Sul, Uruguaiana, RS 
Os espécimens da Coleção FIOC estão conservados em solução de creosoto-terpinol 2:1, e os da Coleção FAGR estão fixados em álcool etílico $70^{\circ}$ G.L. ou foram montados em lâminas para microscopia segundo a técnica proposta por Trois (1982). As ilustrações foram feitas em câmara-clara acoplada a microscópio óptico e sem correções de assimetria; as medidas no texto estão expressas em milimetros. Os tentórios foram visualizados com objetiva de imersão em óleo de cravo.

Gênero Brasixenos Kogan \& Oliveira, 1966

Brasixenos Kogan \& Oliveira, 1966:346.

Xenos Rossius, 1793:49 (sensu Kinzelbach, 1971:160; sinônimo subjetivo, em parte).

\section{Redescrição:}

Macho - Cabeça fortemente transversa, olhos amplamente separados, com mais de 21 omatídios em vista dorsal. Esclerito ante-frontal muito estreito, esclerito pós-frontal muito largo. Mandfbulas longas e delgadas, laminares e com diminutas elevações arredondadas no ápice. Corpos maxilares subcilíndricos ou subcônicos, muito pequenos; palpos maxilares tão longos quanto as mandíbulas e recobertos por cerdas diminutas. Antenas com quatro artículos; primeiro e segundo muito curtos; terceiro curto e flabelado; quarto quase tão longo quanto o flabelo do terceiro; esse, com o flabelo, e o quarto articulo recobertos por sensilas placóides circundadas por microtrlquias.

Tórax: protórax estreito, de aparência bilobada devido às projeções laterais do pré-noto. Acrotergito de formato aproximadamente pentagonal. Mesotórax também estreito, escutos do pré-noto formando uma cinta em torno do acrotergito; o pós-noto é prolongado lateralmente em ambos os lados. Metatórax muito longo, se comparado ao pró e mesotórax; pré-escuto de formato variável entre o pentagonal e o ovalar; escutos amplamente arredondados anteriormente, processo alar anterior agudo na ponta; pré-alar com a margem externa arredondada; escutelo amplamente triangular, extremidades póstero-laterais salientes; pós-lumbio muito largo, arredondado ou ligeiramente agudo na margem distal; fissura escutelo-posescutelar nítida; pós-escutelo muito longo, arredondado na margem distal. Anepímero e pós-coxa estreitos em vista dorsal; méron parcialmente fundido às coxas das pernas posteriores.

Abdómen: urotergitos e urosternitos bem demarcados; ectofalo com formato geral de "S", falobase geralmente mais alargada do que o escapo do edeago, espinho dorsal um pouco prolongado.

Pernas: tarsos dos três pares de pernas com quatro artículos, todos pilosos; basitarso cilindrico e tão longo ou mais longo do que os outros três artículos reunidos; tíbias subcilíndricas, fêmures achatados; trocânteres anteriores e medianos achatados, posteriores subcilfndricos. 
Asas: anteriores halteriformes, de textura pergaminácea, aparentemente com uma nervura do setor radial, posteriores amplas, membranosas, aparentando redução na nervação do setor radial.

Fêmea - Cefalotórax de contorno circular, ligeiramente mais largo do que longo, principalmente ao nível dos espiráculos. Tegumento fracamente quitinizado, fino e transparente, sem áreas pigmentadas. Cabeça estreita, situada em plano inferior ao do tórax. Protórax com a margem anterior bffida, encobrindo a membrana cefalotorácica, que é inconspícua em vista ventral. Mandíbulas mais longas do que largas, com um dente situado na superficie dorsal. tos II a V.

Abdômen: com quatro túbulos genitais situados nos segmen-

Triungulino - Cabeça muito mais larga do que longa; área ocular com cinco omatídios. Apódemas externos côncavos na margem distal da arcada e com as extremidades distais agudas; apódemas internos com as extremidades proximais arredondadas ou agudas e as distais em formato de colher, geralmente torcidas para o lado ventral. Suturas inter-segmentares com fileiras de cerdas curtas. Décimo segmento abdominal com um par de longos estiletes. Tarsos uni-articulados, de contorno semi-elíptico.

Tipo do gênero: Brasixenos fluminensis Kogan \& Oliveira, 1966 (tipo por designação original).

\section{Brasixenos acinctus Kogan \& Oliveira, 1966}

fig. $46,47,53,59)$

Brasixenos acinctus Kogan \& Oliveira, 1966: 356, fig. 52-5, 60-1; Trois, 1984:16.

Xenos (Brasixenos) acinctus: Kinzelbach, 1971:170.

Xenos acinctus: Carvalho, 1978:354.

Redescrição:

Fêmea - Cefalotórax de contorno circular, com uma constrição basal pouco perceptível; coloração geral castanho-clara. Mandíbulas de formato triangular, transversas e uni-denteadas; dente arredondado na ponta e voltado para fora. Abertura bucal muito próxima da margem anterior da cabeça; esclerito hipo-faringeal muito pequeno, margens anterior e posterior quase paralelas. Margem anterior do cefalotórax ligeiramente deprimida, encobrindo a membrana cefalotorácica que é inconspícua em vista ventral. Margem anterior do protórax côncava. Espiráculos metatorácicos situados lateralmente.

Medidas principais: cefalotórax - comprimento 1,10; largura na base 1,50; largura entre os espiráculos 1,20; largura maior 1,50. Ca- 
beça - comprimento na linha mediana 0,12 ; comprimento lateralmente 0,42 ; largura na base 1,26 ; largura ao longo da membrana cefalotorácica 0,94 ; distância entre as mandíbulas 0,30 .

Triungulino - Coloração geral castanho-clara. Comprimento total sem os estiletes abdominais 0,20 ; largura maior 0,13 .

Cabeça: comprimento 0,04; largura na base 0,05 . Área ocular com quatro omatídios dorșalmente e um na face ventral. Três pares de cerdas na parte distal da área ocular, no lado dorsal, e dois pares no lado ventral. Tentório com os apódemas externos dobrados em ângulo de $90^{\circ}$, côncavos na margem interna e pontiagudos nas extremidades proximal e distal dos ramos longitudinais; apódemas internos com um espinho agudo próximo à extremidade proximal e em forma de colher na distal.

Tórax: pró, meso e metatórax sub-iguais, mas gradualmente mais largos no sentido distal. Escleritos esternais sem suturas perceptíveis. Franjas de pequenos pelos emarginam posteriormente os segmentos.

Abdômen: segmentos I a VII progressivamente estreitados para a extremidade distal; oitavo segmento apresentando duas cerdas dorsalmente; o nono mais longo do que os segmentos precedentes e com um par de cerdas que se articulam em processos tubulares do urosternito e dois outros pares laterais; décimo segmento curto e com um par de longos estiletes.

Pernas: coxas largas e com alguns espinhos laminares na margem interna e uma longa cerda orientada distalmente. Trocânterofemur com duas cerdas na margem interna. Tíbias longas e sub-cilindricas. Tarsos elipticos e achatados.

Macho - desconhecido.

Hospedeiro - Polybia sp. (Vespidae, Hymenoptera).

Distribuição - BRASIL: Rio de Janeiro.

Material examinado - série-tipo: BRASIL, Rio de Janeiro, Deodoro, holótipo, q, FIOC 0082, 02/11/1934, W. Zican leg.; parátipos, dois triungulinos, FIOC 0082A-B, mesmos dados do holótipo.

Brasixenos araujoi (Oliveira \& Kogan, 1962) Kogan \& Oliveira, 1966 (Fig. 48,54,60)

Xenos araujoi Oliveira \& Kogan, 1962:6, fig. 3, 17-21; Carvalho, 1978: 354. 
Brasixenos araujoi: Kogan \& Oliveira, 1966: 358; Trois, 1984:16. Xenos (Brasixenos) araujoi: Kinzelbach, 1971:170.

Redescrição:

Fêmea - Cefalotórax constrito na base, inteiramente castanho-claro. Forma geral subovalar, quase circular. Mandíbulas uni-denteadas, 0 dente ligeiramente pontiagudo e voltado para fora. Abertura bucal arredondada; esclerito hipofaringeal com a margem anterior côncava e a posterior retilínea. Membrana cefalotorácica quase que reduzida a uma linha retilinea, pouco perceptivel em vista ventral, e quase atingindo as margens do cefalotórax.

Medidas principais: cefalotórax - comprimento 1,08; largura na base 0,96; largura entre os espiráculos 1,10; largura maior 1,10. Cabeça - comprimento na linha mediana 0,18 ; comprimento lateralmente 0,48 ; largura na base 0,50 ; largura ao longo da membrana cefalotorácica 0,75 ; distância entre as mandíbulas 0,33.

Triungulino - Corpo alongado; coloração geral castanho-clara. Comprimento total sem os estiletes abdominais 0,25; largura maior 0,08.

Cabeça: comprimento 0,05 ; largura na base 0,06 . Área ocular aparentemente com cinco omatídios, um deles parcialmente ventral; contíguos à área ocular existem dois pares de cerdas muito pequenas, na área ventral existe outro par de cerdas pequenas e finas articuladas em pequenos tubérculos. Tentório com os apódemas externos dobrados em ângulo reto, margem interna da arcada côncava, margens externa e lateral ligeiramente sinuosas, e extremidades distais um pouco arredondadas; apódemas internos com dois espinhos na base e em forma de "C", e arredondados na ponta, a extremidade distal em formato de colher e voltados para o lado ventral.

Tórax: segmentos torácicos subiguais na largura. Pronoto com três pares de cerdas muito pequenas, um par distal, outro par próximo à sutura pró-mesonotal dirigido distalmente, e outro par situado lateralmente. Mesonoto e metanoto com dois pares de cerdas em cada segmento, um par lateral e outro sutural. Esternitos glabros.

Abdômen: segmentos progressivamente estreitados para a extremidade distal. Oitavo urotergito com um par de cerdas robustas. Urotergitos I a VIII com cerdas látero-posteriores; urosternitos I a VIII com um feixe de pelos muito finos; nono segmento longo, décimo curto e estiletes longos.

Pernas: coxas largas, com alguns espinhos laminares de comprimentos diferentes nas margens internas, e uma longa cerda dirigida distalmente. Tarsos subelipticos e achatados. 
Revta bras. Zool.

Macho - desconhecido. noptera).

Hospedeiro - Apoica pallens (Fabricius, 1804) (Vespidae, Hyme-

Distribuição - BRASIL: Amazonas

Material examinado - Série-tipo. BRASIL, Amazonas, Manaus, holótipo, \&, FIOC 0028, VI/1941, Parko leg.; parátipos, dois triungulinos, FIOC 0029A-B, mesmos dados do holótipo.

Brasixenos bahiensis Kogan \& Oliveira, 1966

(Fig. 1, 6, 11, 16, 21, 26, 31, 35, 36, 37, 49, 55, 61)

Brasixenos bahiensis Kogan \& Oliveira, 1966:353, fig. 44-7, 56-7;

Hofling \& Machado, 1979:687; Trois, 1984: 16, fig. 5-14.

Xenos (Brasixenos) bahiensis: Kinzelbach, 1971:170.

Xenos bahiensis: Carvalho, 1978:354.

Redescrição:

Macho - Coloração geral do espécimen em álcool: antenas, olhos compostos, asas anteriores e tórax castanho-escuros; cabeça, pernas e abdômen castanho-claros; asas posteriores hialinas.

Cabeça: largura maior 0,99; largura entre os olhos (linha anterior) 0,46 ; (linha mediana) 0,44 ; (linha posterior) 0,44 . Olhos com cerca de 25 omatídios em vista dorsal, microtriquias internomatidiais curtas e densas. Tubérculo frontal ligeiramente arredondado na fronte, excedendo ligeiramente a linha dos olhos. Área epicraniana uniforme. Mandíbulas longas e delgadas, achatadas, agudas na ponta e ultrapassando a abertura bucal. Corpos maxilares muito curtos; palpos maxilares quase tão longos quanto as mandíbulas, recurvados na porção mediana, estreitados na base e no ápice, e inteiramente recobertos por cerdas diminutas regularmente distribuídas. Antenas com o terceiro artículo mais o flabelo e o quarto artículo inteiramente recobertos por sensilas placóides, circundadas por microtríquias; comprimento dos artículos antenais: I e II juntos 0,08; III (com o flabelo) 1,06; IV 1,08; o flabelo do terceiro atingindo $6 / 7$ do comprimento do quarto artículo.

Tórax: pró e mesotórax estreitos, esse cerca de duas vezes e meia mais longo e largo do que aquele. Metatórax com o pré-escuto quase tão largo quanto longo, ligeiramente pontiagudo na frente, quase três vezes mais curto que o escutelo triangular. Pós-lumbio amplo, prolongado anterior e posteriormente em margens amplamente arredondadas. Pós-escutelo muito longo, constrito ao nível do pós-lumbio, alargando-se e constringindo-se novamente até a extremidade arredondada. Comprimento dos escleritos metatorácicos: pré-escuto $\div$ escutelo 0,70 ; pós-lumbio $\div$ pós-escutelo 1,37; comprimento total do metatórax 2,07; largura nos escutos 0,96 . 
Abdómen: ectofalo em forma de "S", espinho dorsal pouco prolongado; acúmen alongado, quase em ângulo reto com o escapo do edeago, que é duas vezes mais fino do que a falobase, essa é amplamente arredondada na margem externa. Proctígero sub-retangular, encaixado no nono urômero, que possui um processo articular na extremidade distal.

Pernas: trocånteres anteriores e medianos quase tão longos quanto os fêmures correspondentes, trocânteres posteriores muito pequenos. Fêmur anterior fino e achatado, fêmures medianos e posteriores largos e achatados. Tíbias dos três pares de pernas finas e subcilíndricas. Tarsos delgados e pilosos, basitarso cilíndrico nos três pares, alongado, quase do mesmo tamanho dos outros três artículos reunidos.

Asas: anteriores com uma nervura no setor radial, que atinge a base de expansão apical das asas; mediana apenas indicada por uma estria pigmentada. Posteriores com a área costal pigmentada; primeira nervura radial terminando na metade do comprimento da margem costal, bifurcada na ponta; segunda radial iniciando em continuação à extremidade inferior da bifurcação da primeira; terceira radial iniciando antes da bifurcação da primeira; quarta radial estendendo-se regularmente desde a base; mediana anterior, primeira e segunda cubitais anteriores estendendo-se até quase a margem da asa; cubital posterior difusa em estria pigmentada.

Fêmea - Cefalotórax constrito na base, forma geral: subcircular; sem banda basal (plica basalis); coloração geral: castanho-clara. Mandibulas uni-denteadas, dentes retos e arredondados na ponta. Abertura bucal situada próximo à margem anterior da cabeça; esclerito hipofaringeal pequeno e com as margens anterior e posterior côncavas. Membrana cefalotorácica pouxo perceptível em vista ventral. Margem anterior do protórax amplamente bi-sinuosa. Espiráculos situados lateralmente.

Medidas principais: cefalotórax - comprimento 1,16; largura na base 1,14; largura entre os espiráculos 1,16; largura maior 1,30. Cabeça - comprimento na linha mediana 0,18 ; comprimento lateralmente 0,48 ; largura na base 1,16; largura ao longo da membrana cefalotorácica 0,64; distância entre as mandíbulas 0,26.

Triungulino - Coloração geral: castanho-clara; comprimento total sem os estiletes abdominais 0,16 ; largura maior 0,08 .

Cabeça: comprimento 0,03 , largura na base 0,02 . Área ocular com cinco omatídios, um dos quais situado latero-ventralmente. Um par de cerdas situado próximo à área ocular, na margem proximal do lado ventral. Tentório com os apódemas externos quase em ângulo reto, margens anterior e lateral bi-sinuosas, agudos nas extremidades proximal e distal, as distais convergentes; apódemas internos com dois es- 
pinhos na base, em formato de " $V$ " e arredondados na ponta, extremidades distais em formato de colher e ligeiramente torcidos no sentido proximal.

Tórax: pró e mesotórax de largura subigual. Pró, meso e metasterno sem estruturas perceptíveis. Margens posteriores dos segmentos emarginadas por franjas de pequenos pelos.

Abdômen:segmentos I a VII estreitados progressivamente para a extremidade distal; o oitavo apresenta duas cerdas dorsalmente; nono segmento mais longo do que qualquer outro segmento abdominal, com um par de cerdas longas articuladas em processos tubulares no lado ventral, e dois outros pares iniciando nas margens laterais; décimo segmento curto e com um par de longos estiletes.

Pernas: coxas largas, com espinhos laminares na margem interna e uma longa cerda orientada distalmente; trocântero-fêmures com esinhos nas margens internas; tíbias estreitas e também com espinhos nas margens internas; tarsos semi-elfpticos.

Hospedeiro - Polybia ignobillis (Haliday, 1836) (Vespidae, Hymenoptera).

Distribuição - BRASIL: Bahia e São Paulo.

Material examinado - Série-tipo: BRASIL, Bahia, Salvador, holótipo, \&, FIOC 0077A, 26/02/1959, S. J. Oliveira \& A. de Jesus leg.; parátipos, triungulinos, FIOC 0077B, mesmos dados do holótipo. Outro material examinado: BRASIL, São Paulo, Rio vilaro, um ô, FAGR 0032, dez. 1978, J. C. Hofling leg. ; trâs $q+$, FAGR 0033 a 0035, mesmos dados do macho; doze pupas de ơ ô com pupários, FAGR 0036 a 0047 , mesmos dados do macho.

Brasixenos brasiliensis Kogan \& Oliveira, 1966 (Fig. 50, 56, 62)

Brasixenos brasiliensis Kogan \& Oliveira, 1966:355, fig. 48-51, 58-9; Trois, 1984:16.

Xenos (Brasixenos) brasiliensis: Kinzelbach, 1971:170.

Xenos brasiliensis: Carvalho, 1978:354.

Redescrição:

Fêmea - Cefalotórax ligeiramente constrito na base, inteiramente castanho-claro, sem banda basal, e de contorno subcircular. Mandíbulas uni-denteadas, o dente arredondado na ponta e voltado para fora. Abertura bucal situada próximo à margem anterior da cabeça; esclerito hipofaringeal muito pequeno, e com a margem anterior amplamente côncava. Membrana cefalotorácica estreita em vista ventral, não atingindo as margens do cefalotórax, e parcialmente encoberta nas extremidades 
pelas projeçōes do protórax que é côncavo. Espiráculos situados lateralmente na metade do comprimento do cefalotórax.

Medidas principais: cefalotórax - comprimento 1,40; largura na base 1,48; largura entre os espiráculos 1,21; largura maior 1,50. Cabeça - comprimento na linha mediana 0,12 ; comprimento lateralmente 0,50 ; largura na base 0,64 ; largura ao longo da membrana cefalotorácica 0,80 ; distância entre as mandíbulas 0,30 .

Triungulino - Coloração geral: castanho-clara. Comprimento total sem os estiletes abdominais 0,21 ; largura maior 0,11 .

Cabeça: comprimento 0,04; largura na base 0,05. Área ocular com cinco omatídios dorsalmente e um ventralmente. Um par de cerdas contíguo à área ocular, na margem distal do lado dorsal, e um par próximo à região proximal no lado ventral. Tentório com os apódemas externos dobrados em ângulo reto, margens externas bi-sinuosas, margem interna da arcada côncava, e extremidades distais pontiagudas; apódemas internos tendo na base dois espinhos, um arredondado e outro pontiagudo, extremidades distais em formato de colher e torcidas para o lado ventral.

Tórax: pró, meso e metatórax aproximadamente do mesmo comprimento e largura, o protórax aparenta ser um pouco mais largo do que os demais segmentos; os três segmentos com pares de pelos diminutos nas margens distais. Pró, meso, e metasterno sem estruturas perceptiveis.

Abdômen: segmentos I a VII estreitados progressivamente para a extremidade distal; oitavo apresentando duas cerdas na área tergal, nono apresentando um par de cerdas articuladas em processos tubulares no lado ventral e muito mais longo do que os outros segmentos, ainda dois outros pares de cerdas iniciam nas margens laterais; o décimo é curto e com um par de longos estiletes apicais.

Pernas: coxas largas com espinhos laminares na margem interna; trocântero-fêmures e tíbias semelhantes no tamanho, essas com pequenos pelos irregularmente distribuídos, tarsos uni-articulados e semi-elípticos.

Macho - desconhecido.

Hospedeiro - Polybia sericea (Olivier, 1791) (Vespidae, Hymenoptera).

Distribuição - BRASIL: Pará e Rio de Janeiro.

Material examinado - Série-tipo: BRASIL, Rio de Janeiro, Itatiaia, holótipo, +, FIOC 0075, 05/04/1939, J. F. Zican leg.; BRASIL, Pará, Cachimbo, parátipos, + , FIOC 0073A e 0074A, 12/01/1956 e 06/06/1956, respectivamente, Travassos \& Adão leg.; parátipos, triungulinos, FIOC 0073B e 0074b, mesmos dados dos parátipos, respectivamente. 
Brasixenos fluminensis Kogan \& Oliveira, 1966

(Fig. 2, 7, 12, 17, 22, 27, 38, 39, 51, 57, 63)

Brasixenos fluminensis Kogan \& Oliveira, 1966:347, fig. 1-5, 14-22;

Trois, 1984:16.

Xenos (Brasixenos) fluminensis: Kinzelbach, 1971:170.

Xenos fluminensis: Carvalho, 1978:354.

Redescrição:

Macho - Cabeça: Iargura maior 1,00; largura entre os olhos 0,78. Olhos com cerca de 25 omatídios em vista dorsal; microtríquias interomatidiais muito curtas e densas. Tubérculo frontal apenas pronunciado em ângulos obtuso na margem anterior, arredondado no vértice e limitado, nas margens laterais, pela base das antenas. Pós-fronte e placa do vértice pouco nítidas. Mandíbulas longas, ultrapassando a abertura bucal, delgadas e achatadas, ápice ligeiramente arredondado e com duas ou três elevações muito pequenas. Corpos maxilares muito curtos; palpos maxilares um pouco menos do que $1 / 4$ mais curtos do que as mandibulas, mas mais largos do que essas, e inteiramente cobertos por diminutas cerdas regularmente distribuídas. Antenas com os artículos do escapo muito pequenos e sem estruturas perceptiveis; terceiro artículo com o flabelo e mais o quarto artículo inteiramente cobertos com sensilas placóides, emarginadas por pelos diminutos; comprimento dos articulos antenais: I e II juntos, 0,16 ; III (com o flabelo) 0,80 ; IV 1,18; o flabelo do terceiro atingindo no máximo $4 / 5$ do comprimento do quarto artfculo.

Tórax: protórax bilobado lateralmente, mais do que duas vezes mais largo do que longo. Mesotórax com o escuto mais largo do que o pré-escuto, esse tão largo quanto o protórax. Metatórax com o préescuto amplamente arredondado na margem anterior, mais longo do que largo e tão longo quanto o escutelo sub-triangular; pós-lumbio muito amplo, margem anterior côncava e posterior convexa; pós-escutelo longo e de contorno ligeiramente sinuoss; comprimento dos escleritos metatorácicos: pré-escuto $\div$ escutelo 1,00 ; pós-escutelo $\div$ pós-lumbio 1,24, comprimento total do metatórax 2,24; largura nos escutos 0,75 .

Abdômen: ectofalo com o espinho dorsal ligeiramente prolongado, acúmen alongado e formando um ângulo de cerca de $70^{\circ} \mathrm{com}$ o escapo do edeago, esse é quase tão espesso quanto a falobase que apresenta fina pubescência na articulação com o nono urômero, esse apresenta na região esternal, e distal, um processo articular em forma de gancho; proctigero sub-retangular.

Pernas: coxas anteriores e medianas curtas e sub-cilíndricas, posterior muito pequenas e encaixadas no méron; trocânteres anteriores e medianos tão longos quanto os fêmures correspondentes, poste- 
riores muito pequenos e sub-cilindricos; fêmures dos dois primeiros pares de pernas longos, achatados e com o sulco mediano conspicuo; fêmures posteriores e todas as tíbias longos, delgados e subcillndricos; a semelhança dos tarsos, cujos basitarsos são mais longos do que os outros três artículos tarsais juntos, e apresentam o órgão-de-Hofeneder na região mediana da margem interna.

Asas: não examinadas por estarem muito enrrugadas e diafanizadas.

Fêmea - Cefalotórax não constrito na base, coloração castanhoclara; formato geral: quase que regularmente circular. Mandibulas unidenteadas, o dente arredondado na ponta e ligeiramente voltado para fora. Esclerito hipofaringeal na mesma linha da margem anterior da cabeça; abertura bucal situada muito próximo do esclerito hipofaringeal. Membrana cefalotorácica quase inconspicua em vista ventral, não alcançando as margens do cefalotórax. Espiráculos metatorácicos situados lateralmente na metade do comprimento do cefalotórax.

Medidas principais: cefalotórax - comprimento 1,16; largura na base 1,04; largura entre os espiráculos 1,00; largura maior 1,20. Cabeça - comprimento na linha mediana 0,16 ; comprimento lateralmente 0,32 ; largura na base 0,96 , largura ao longo da membrana cefalotorácica 0,70 ; distância entre as mandíbulas 0,28 .

Triungulino - Tentório com os apódemas externos dobrados em ângulo de quase $90^{\circ}$, arcada côncava na margem interna, ramos longitudinais sinuosos, extremidades distais pontiagudas; base dos apódemas internos com dois espinhos arredondados na ponta, em forma de "C" e orientados no sentido proximal, extremidades distais laminares e também torcidas no sentido proximal. ra).

Hospedeiro - Polybia atra Saussure, 1853 (Vespidae, Hymenopte-

Distribuição - BRASIL: Rio de Janeiro.

Material examinado - Série-tipo: BRASIL, Rio de Janeiro, Itagual, holótipo, ô, FIOC 0076, 23/09/1946, Miranda leg.; alótipo, + , FIOC 0132A, mesmos dados do holótipo; parátipo, triungulino, FIOC 0132B, mesmos dados do holótipo.

Brasixenos myrapetrus, $s p . n$.

(Fig. 3, 8, 13, 18, 23, 28, 32, 40, 41, 52, 58)

Macho - Coloração geral do espécimen em álcool: antenas, asas anteriores e tórax castanho-escura, quase preta; olhos compostos pretos; cabeça, abdômen e pernas castanho-claras; asas posteriores hialinas. 
Cabeça: largura maior 0,80; largura entre os olhos (linha anterior) 0,80 , (linha mediana) 0,76 ; (linha posterior) 0,78 . Olhos com cerca de 22 omatídios em vista dorsal, microtríquias inter-omatidiais curtas e densas. Tubérculo frontal ligeiramente arredondado, pouco perceptível em vista dorsal, pois o clípeo excede um pouco a linha dos olhos. Área epicraniana uniforme, prolongada látero-distalmente. Mandíbulas longas, sinuosas, achatadas, agudas nas pontas e ultrapassando a abertura bucal. Corpos maxilares muito curtos; tanto que aparentam ser hemisféricos; palpos maxilares quase do comprimento das mandíbulas, um pouco espessados na base, subcilíndricos no restante do comprimento, agudos na ponta, com um feixe de cerdas próximo ao ápice e inteiramente cobertos por cerdas diminutas. Antenas com o terceiro artículo mais o flabelo, e o quarto artículo, cobertos de sensilas, circundadas por microtriquias. Comprimento dos artículos antenais: I e II juntos 0,10; III (com o flabelo) 0,99; IV 1,14; o flabelo do terceiro atingindo $7 / 8$ do comprimento do quarto artículo.

Tórax: pró e mesotórax estreitos, esse cerca de 2,2 vezes mais longo do que aquele. Metatórax com o pré-escuto quase tẳo longo quanto largo, ângulos anteriores arredondados e laterais agudos, quase três vezes mais curto do que o escutelo triangular. Pós-lumbio amplo, prolongado no sentido proximal e distal em margens amplamente arredondadas. Pós-escutelo longo, constrito ao nivel do pós-lumbio e com o anepimero visível em plano inferior, o pós-escutelo ainda alarga-se e constringe-se novamente até a extremidade arredondada. Comprimento dos escleritos metatorácicos: pré-escuto $\div$ escutelo 0,74 ; pós-lumbio $\div$ pós-escutelo 1,23; comprimento total do metatórax 1,97; largura ao nível dos escutos 0,76 .

Abdômen: ectofalo em forma de "S", espinho dorsal pouco prolongado; acúmen alongado, quase em ângulo reto com o escapo do edeago, que é duas vezes mais fino do que a falobase, essa é amplamente larga e um pouco arredondada na margem externa. Proctígero sub-retangular até a extremidade distal que é ligeiramente afilada, hipopigio triangular.

Pernas: coxas anteriores pequenas, medianas inconspicuas, posteriores parcialmente fundidas ao méron. Trocânteres anteriores e medianos longos e achatados, posteriores curtos e subtriangulares em vista ventral. Tíbias dos três pares de pernas longas e subcilíndricas. Basitarsos dos três pares de pernas quase tão longos quanto os outros artículos tarsais juntos.

Asas: anteriores halteriformes, alargadas no ápice e para o sentido distal; uma nervura no setor radial, curvada para a região proximal e atingindo a expansão apical. Posteriores com as nervuras da área costal terminando além da metade do comprimento da margem costal; primeira e segunda radiais estendendo-se desde quase a base 
até quase a margem da asa; terceira curta e sinuosa; quarta estendendo-se regularmente da base até quase a margem; medianas anterior e posterior também estendendo-se quase que regularmente desde a base até a margem da asa.

Fêmea - Cefalotórax de contorno quase circular, constrito na base; coloração geral: castanho-clara. Mandibulas subtriangulares, alongadas, com um dente quase reto e arredondado na extremidade. Abertura bucal conspicua; esclerito hipofaringeal com a margem anterior côncava, muito grande e situado entre a abertura bucal e a membrana cefalotorácıca; esta nao é perceptível em vista ventral. Protórax com as margens anterior e laterais côncavas. Espiráculos situados lateralmente.

Medidas principais: cefalotórax - comprimento 1,14; largura na base 0,99; largura entre os espiráculos 1,13; largura maior 1,16. Cabeça - comprimento na linha mediana 0,15 ; comprimento lateralmente 0,34 ; largura na base 1,00; largura ao longo da membrana cefalotorácica 0,72; distância entre as mandíbulas 0,25.

Triungulino - desconhecido.

Hospedeiro - Polybia (Myrapetra) paulista (Ihering, 1896) (Vespidae, Hymenoptera).

Distribuição - BRASIL: São Paulo.

Série-tipo - BRASIL, São Paulo, Rio Claro, holótipo, đ, FAGR 0048, 22/08/1978, V. L. L. Machado leg.; alótịpo, \&, FAGR 0050, mesmos dados do holótipo; parátipos, um ò e duas qq, FAGR 0049, 0051 e 0052 respectivamente, mesmos dados do holótipo. Outro material: sete pupas e pupários de ổ, FAGR 0053A a 0058, mesmos dados do holotipo.

Brasixenos occidentalis Kogan \& Oliveira, 1966

(Fig. 4, 9, 14, 19, 24, 29, 33, 42, 43)

Brasixenos occidentalis Kogan \& Oliveira, 1966:352, fig. 10-3, 32-9;

Trois, 1984:16.

Xenos (Brasixenos) occidentalis: Kinzelbach, 1971:170.

Xenos occidentalis: Carvalho, 1978:354.

Redescrição:

Macho - Cabeça: largura maior 0,92; largura entre os olhos (linha anterior) 0,44; (linha posterior) 0,60. Olhos com cerca de 23 omatídios em vista dorsal, microtrqquias interomatidiais curtas e densas. Tuberculo frontal prolongado anteriormente em ângulo obtuso, arredondado no vértice, e excedendo ligeiramente a linha dos olhos na frente. Área epicraniana uniforme. Mandíbulas longas, delgadas e achatadas, agudas 
na ponta, ligeiramente torcidas e ultrapassando a abertura bucal. Corpos maxilares muito pequenos; palpos maxilares tão longos quanto as mandíbulas, lineares, terço basal alargado, terço apical de margens paralelas; inteiramente recobertos por cerdas curtas regularmente distribuidas. Antenas com o terceiro artículo mais o flabelo, e o quarto articulo, recobertos por sensilas placóides emarginadas por microtriquias. Comprimento dos artículos antenais: I e II juntos 0,16; III (com o flabelo) 0,98 ; IV 1,05 ; o flabelo do terceiro atingindo cerca de $7 / 8$ do comprimento do quarto artículo.

Tórax: protórax bilobado lateralmente, devido às expansōes do pós-noto, e cerca de 3,5 vezes mais largo do que longo. Pré-escuto do mesotórax um pouco mais estreito do que o protórax; escuto mais largo do que o protórax. Metatórax com o pré-escuto quase tão longo quanto largo, muito mais curto do que o escutelo triangular; pós-lumbio longo e largo, margens anterior e posterior amplamente côncavas; pósescutelo relativamente curto, margens laterais convergentes até a extremidade distal arredondada. Comprimento dos escleritos metatorácicos: pré-escuto $\div$ escutelo 0,76 ; pós-lumbio $\div$ pós-escutelo 1,20 ; comprimento total do metatórax 1,96; largura nos escutos 0,77 .

Abdômen: ectofalo em forma de "S"; espinho dorsal ligeiramente prolongado; acúmen longo e formando um ângulo de quase $80^{\circ}$ com o escapo do edeago que é um pouco menos espesso do que a falobase.

Pernas: trocânteres anteriores e medianos tão longos quanto os fêmures correspondentes, que também são delgados e achatados; trocânteres posteriores pequenos e subcilindricos. Todas as tŕbias finas e subcilíndricas. Tarsos delgados e pilosos, basitarso tão longc quanto o segundo e terceiro articulos juntos.

Asas: anteriores halteriformes, com apenas uma nervura indicada no setor mediano. Posteriores com a área costal pigmentada; primeira radial interrompida na metade do comprimento da margem costal e voltada para a base na extremidade, segunda radial iniciando logo após a primeira, mas não em prolongamento a essa; terceira radial iniciando ao meio do comprimento da quarta radial; quarta radial, mediana anterior $e$ as duas cubitais anteriores estendendo-se desde a base sem interrupções; cubital posterior difusa em estria pigmentada.

Fêmea e triungulino - desconhecidos.

Hospedeiro - Polybia occidentalis (Olivier, 1791) (Vespidae, Hymenoptera).

Distribuição - BRASIL: Mato Grosso.

Material examinado - Série-tipo: BRASIL, Mato Grosso, Salobra, holótipo, ठิ, FIOC 0080, 24/08/1940, Comissão Científica Instituto Oswaldo Cruz leg. 
Brasixenos zikani Kogan \& Oliveira, 1966

(Fig. 5, 10, 15, 20, 25, 30, 34, 44, 45)

Brasixenos zikani Kogan \& Oliveira, 1966:350, fig. 6-9, 23-31;

Trois, 1984:16.

Xenos (Brasixenos) zikani: Kinzelbach, 1971:170.

Xenos zikani: Carvalho, 1978:354.

Redescrição:

Macho - Cabeça: largura maior 0,92; largura entre os olhos (linha anterior) 0,50 . Olhos com cerca de 27 omatídios em vista dorsal; microtríquias interomatidiais curtas e densas. Tubérculo frontal prolongado anteriormente, mas sem exceder a linha dos olhos na frente, e com duas pequenas gibosidades na superfície dorsal. Área epicraniana uniforme, esclerito pós-frontal largo, vértice expandido nos sentidos laterodistais. Mandf́bulas longas e delgadas, achatadas e agudas na ponta, ligeiramente sinuosas e ultrapassando a abertura bucal. Corpos maxilares muito pequenos, quase hemisféricos; palpos maxilares $1 / 8$ mais curtos do que as mandíbulas, lineares, espessados na metade basal, mas gradualmente estreitados até o ápice arredondado, e recobertos desde a base por cerdas regularmente distribuldas. Antenas com o terceiro artículo, mais o flabelo, e o quarto artículo cobertos por sensilas placóides, emarginadas por microtríquias; comprimento dos artículos antenais: I e II juntos 0,16 ; III (com o flabelo) 1,02; IV 1,12; o flabelo do terceiro atingindo $7 / 8$ do comprimento do quarto artículo.

Tórax: protórax bilobado lateralmente, devido ao pré-noto e pósnoto globosos, e 2,5 vezes mais largo do que longo. Mesotórax com o escuto tão largo quanto o protórax. Metatórax com pré-escuto quase tão longo quanto largo, um pouco deprimido anteriornente em ambos os lados, muito mais curto do que o o escutelo triangular; pós-lumbio muito amplo, expandido anterior e posteriormente en margens arredondadas; pós-escutelo relativamente curto, margens laterais pouco convergentes e arredondado na extremidade; comprimento dos escleritos metatorácicos: pré-escuto $\div$ escutelo 0,72 ; pós-lumbio $\div$ pós-escutelo 1,22 ; comprimento total do metatórax 1,94; largura ao nivel dos escutos 0,75 .

Abdômen: nono urômero quase tão longo quanto largo; proctígero sub-triangular, cerca de 1,5 vez mais longo do que largo, ectofalo em forma de "S", espinho dorsal pouco alongado, acúmen longo e formando um ângulo de $70^{\circ}$ com o escapo do edeago, falobase cerca de duas vezes mais curta e espessa do que o escapo do edeago.

Pernas: trocânteres anteriores e medianos tão longos quanto os fêmures correspondentes, trocânteres posteriores curtos e subcilíndricos; fêmures achatados e tíbias subcillndricas; tarsos delgados e pilosos, basitarso apenas um pouco mais curto do que os outros articulos tarsais juntos. 
Revta bras. Zool.

Asas: anteriores halteriformes, com apenas uma nervura no setor mediano. Posteriores com a área costal pigmentada; primeira radial interrompida na metade do comprimento da margem costal, segunda radial em prolongamento à primeira, terceira radial iniciando perto da metade do comprimento da quarta radial e não alcançando a margem da asa; quarta radial, mediana anterior e as duas cubitais anteriores estendendo-se regularmente até a margem da asa; cubital posterior difusa em estria pigmentada.

Fêmea e triungulino - desconhecidos.

Hospedeiro - Polybia ypiranguensis Ihering, 1904 (Vespidae, Hymenoptera).

Distribuição - BRASIL: Rio de Janeiro.

Material examinado - Série-tipo. BRASIL, Rio de Janeiro, Itatiaia, holótipo, ơ, FIOC 0081, 07/01/1941, F. Zikan leg.

\section{DISCUSSÃO}

Ao estabelecerem o gênero Brasixenos, Kogan \& Oliveira (1966) apresentaram uma discussão sobre as relações filogenéticas com outros gêneros de Strepsiptera, cujos representantes parasitam vespas da sub-família Polybiinae. Dessa maneira, trataram da proximidade sistemática com o gênero Belonogastechthrus Pierce, 1911, de distribuição etiópica, e Clypoxenos Bréthes, 1922, de distribuição neotropical. Referiram ainda que a escassez de material sobre esses gêneros, impedia 0 estabelecimento de relações sistemáticas precisas com outros gêneros, inclusive com Brasixenos.

Em 1971, Kirızelbach propôs uma nova combinação para o gênero Xenos Rossius, 1793, na qual incluiu Vespaexenos (Pierce, 1909), Belonogastechthrus, Clypoxenos e Brasixenos ao nivel de sub-gênero. Outro subgênero, Niponnoxenos, foi estabelecido posteriormente por Kifune \& Maeta (1975).

No entanto, as espécies de Brasixenos constituem uma unidade taxonômica ao nivel de gênero, na medida em que se considera que os machos apresentam dissemelhanças ineqüívocas em relação aos machos de Xenos. Tais dissemelhanças se referem ao formato dos escleritos metatorácicos, estabelecido por Pierce (1964) como caracter genérico. O formato dos escleritos do metatórax, afasta filogeneticamente os machos de Brasixenos, não só do gênero Xenos, mas de toda a subfamflia Xeninae (Saunders, 1872). Não obstante, aproxima-os da subfamflia Paraxeninae Kinzelbach, 1971 e Stylopinae (Kirby, 1813).

Os caracteres que aproximam Brasixenos dessas sub-famflias são: pós-lumbio muito largo, pós-escutelo longo, anepímero muito estreito em vista dorsal, e méron parcialmente fundido às coxas posterio- 
res. Além desses caracteres, ainda podem ser considerados os seguintes: esclerito pós-frontal muito largo e corpos maxilares muito pequenos; ambos caracteres secundários.

Por outro lado, podem ser facilmente distinguidos de Paraxeninae, porque os representantes dessa sub-famf́lia parasitam espécimens de ( phecoidea; da mesma maneira, podem ser separados de Stylopinae, cujos representantes parasitam espécimens de Apoidea.

Para a distinção das espécies de Brasixenos, entre si, apresentase a seguinte chave dicotômica:

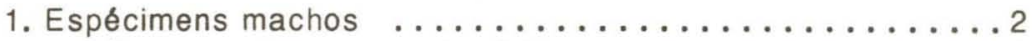

1'. Espécimens fêmeas ou triungulinos $\ldots \ldots \ldots \ldots \ldots \ldots 6$

2. (1). Palpos maxilares retillneos ............... 4

2'. Palpos maxilares com outro aspecto ................

3 (2'). Palpos maxilares arqueados e espessados na regiăo me-

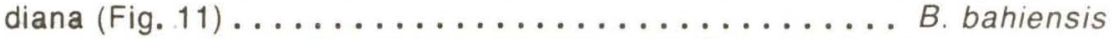

3'. Palpos maxilares sinuosos (Fig. 12). B. fluminensis

4. (2). Palpos maxilares arredondados na ponta ........ 5

4'. Palpos maxilares agudos na ponta e globoso na base (Fig. 13) ....................... myrapetrus, sp. n.

5 (4). Palpos maxilares muito curtos, espessados na netade basal (Fig. 15); escuto de formato ovalar (Fig. 25) ............ B. zikani

5'. Palpos maxilares alongados, espessados no terço basal (Fig. 24); escuto de formato pentagonal (Fig. 14) ....... B. occidentalis

$6\left(1{ }^{\prime}\right)$. Espécimens fêmeas . . . . . . . . . . . . . . 7

6'. Espécimens triungulinos ............... 12

7 (6). Mandibulas da exúvia externa subtriangulares ou subretan-

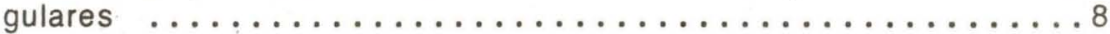

7'. Mandíbulas semi-circulares, mais largas do que longas, dente curto e agudo na ponta (Fig. 53) ................ a. acinctus

8 (7). Mandíbulas subretangulares $\ldots \ldots \ldots \ldots \ldots \ldots$

8'. Mandíbulas sub-triangulares $\ldots \ldots \ldots \ldots \ldots \ldots \ldots \ldots 11$

9 (8). Dentes situados no ângulo apical interno, espessos e arredondados na ponta (Fig. 54); margem anterior do protórax quase retillnea (Fig. 48) ........................................

9'. Dentes afastados do ângulo apical interno .......... 10

$10\left(9^{\prime}\right)$. Dentes nitidamente recurvados para a região lateral (Fig. 55); parasitas de Polybia sericea. . . . . . . . . . . B. brasiliensis

10'. Dentes quase retilíneos (Fig. 56); parasitas de $P$. ignobillis $B$. bahiensis

$11\left(8^{\prime}\right)$. Mandibulas nitidamente mais largas do que longas, dente afastado do ápice, curvo e arredondado na ponta (Fig. 57); esclerito hipofaringeal pequeno (Fig. 51); parasitas de $P$. atra . . . . B. fluminensis 
11'. Mandfbulas aparentemente mais longas do que largas, dente apical e retilfneo (Fig. 58); esclerito hipofaringeal muito largo (Fig. 52); parasitas de $P$. paulista................. myrapetrus, sp. n.

$12\left(6^{\prime}\right)$. Todos os espinhos basais dos apódemas internos do tentório arredondados na ponta .................. 14

12'. Alguns espinhos basais pontiagudos ........... 13

$13\left(12^{\prime}\right)$. Apenas um espinho basal pontiagudo e na margem lateral de cada apódema (Fig. 59) ..................... acinctus

13'. Dois espinhos basais, um pontiagudo e outro arredondado na margem laterai (Fig. 62) .................. brasiliensis

14 (12). Espinhos basais em formato de " $V$ "; extremidades distais dos apódemas externos convergentes (Fig. 61) ....... B. bahiensis 14'. Espinhos basais em forma de "C" ............. 15 araujoi

15 (14). Espinhos basais orientados no sentido lateral (Fig. 60) B.

15'. Espinhos basais orientados no sentido proximal (Fig. 63) . B. fluminensis

\section{AGRADECIMENTOS}

O autor deseja expressar seus agradecimentos ao Dr. Orlando Vicente Ferreira, Dr. José Juberg, Dra. Vera Lígia Letizio Machado e Dr. Gervásio Silva Carvalho, pelo acesso ao material estudado.

\section{REFERÊNCIAS}

BRÈTHES, J. 1922. Primera contribuición para el conocimiento de los "Strepsiptera" argentinos. Revta. Fac. agron. La Plata, 15:41-56, 4 pl.

CARVALHO, E. L. de. 1978. Contribution à l'étude des Strepsiptères du Brésil. Revue suisse Zool., 85(2):353-60, 23 fig.

HOFLING, J. C. \& MACHADO, V. L. L. 1979. Levantamento de Brasixenos bahiensis Kogan \& Oliveira, 1966 (Strepsiptera) em Polybia ignobillis Haliday, 1836 (Hymenoptera, Vespidae). Ciênc. \& Cult., $31(7): 687-8$.

KIFUNE, T. \& MAETA, Y. 1975. A new subgenus and a new species of the genus Xenos (Strepsiptera, Stylopidae) from Japan. III. Studies on the Japan Strepsiptera. Kontyu, 43(4):446-55.

KINZELBACH, R. 1971. Morphologische Befunde an Facherflüglern und ihre phylogenetische Bedeutung (Insecta, Strepsiptera). Zoologica, 119(1/2):1-256, $182 \mathrm{fig}$. 
KOGAN, M. \& OLIVEIRA, S. J. 1966. Brazilian Xenidae parasitizing "Polybia" wasps, with the descriptions of a new genus and six new species (Insecta, Strepsiptera). Revta brasil. biol., 26(4):345-60, 63 fig.

OLIVEIRA, S. J. \& KOGAN, M. 1962. Brazilian Strepsiptera (Insecta) parasitizing Vespidae, with descriptions of three new species of Xenos Rossi, 1793 (Stylopidae). Mems. Inst. Oswaldo Cruz. $\& 0(1): 1-11.30 \mathrm{fig}$.

PIERCE, W. D. 1909. A monographic revision of the twisted winged insects comprising the order Strepsiptera Kirby. Bull. U. S. nat. Mus., 66:1-232, 3 fig., 15 pl., 1 mapa.

PIERCE, W.D. 1911. Notes on insects of the order Strepsiptera with descriptions of new species. Proc. U. S. nat. Mus., 40: 487-511.

PIERCE, W. D. 1964. The Strepsiptera are a true order, unrelated to Coleoptera. Ann. ent. Soc. Amer., 57:603-5.

SAUNDERS, S. S. 1872. Stylopidarum, ordinen Strepsipterorum Kirby constituentium, nihi tamen potius Coleopterorum Familiae, Rhipiphoridis Meloidisquae propinquae, Monographia. Trans. ent. Soc. Londcn. 1872, pag. 1-42, 287-8, 15 fig.

TRCIS, C. A. C. 1982. Contribuição para o conhecimento do gênero $\mathrm{Ha}$ lictoxenos Pierce, 1908 (Insecta, Strepsiptera, Stylopidae). Iheringia Pierce, 1908 (Insecta, Strepsiptera, Stylopidae). Iheringia, sér. Zoclogia, 61:91-6, 6 fig.

TRCIS, C. A. C. 1984. Strepsiptera brasleiros. II. Umia nova espécie de Paraxenos Sauncers, 1872, e a descrição do macho de Brasixenos bahiersis Kogan \& Cliveira, 1966 (Stylopidae, Insecta). Iheringia, sér. Zocilogia, (64):15-21, 14 fig. 

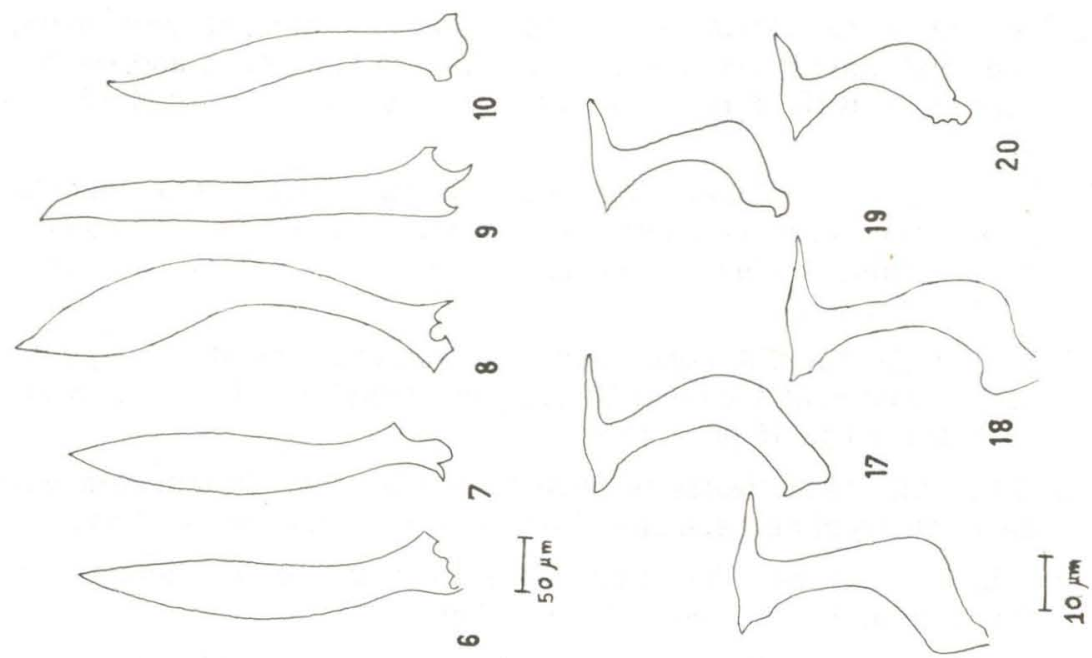

$\infty$

ю
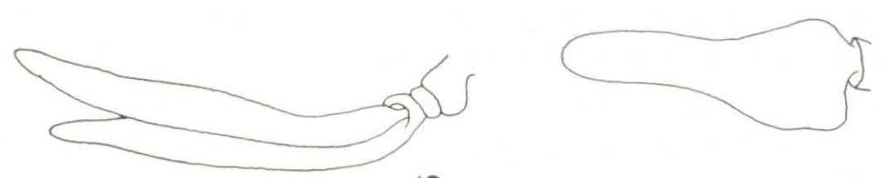

$\cong$
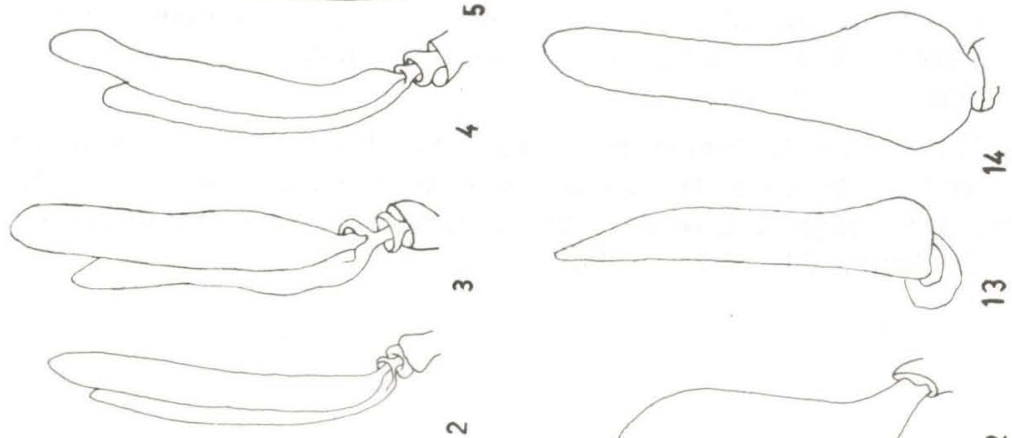

$\sim$

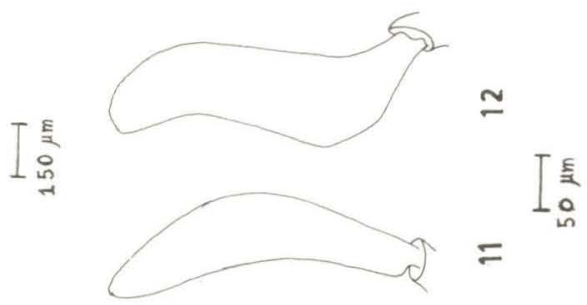

Plancha I - Antenas, mandfbulas e palpos maxilares, lado direito vista ventral. Ectofalos, vista lateral. Fig. 1, 6, 11 e 16: $B$. bahiensis, FAGR 0032. Fig. 2, 7, 12 e 17: B. fluminensis, holótipo. Fig. 3, 8, 13 e 18: B. myrapetrus, sp.n., holótipo. Fig. 4, 9, 14 e 19: B. occidentalis, holótipo. Fig. 5, 10, 15 e 20: B. zikani, holótipo. 
Vol. $5(2), 1988$
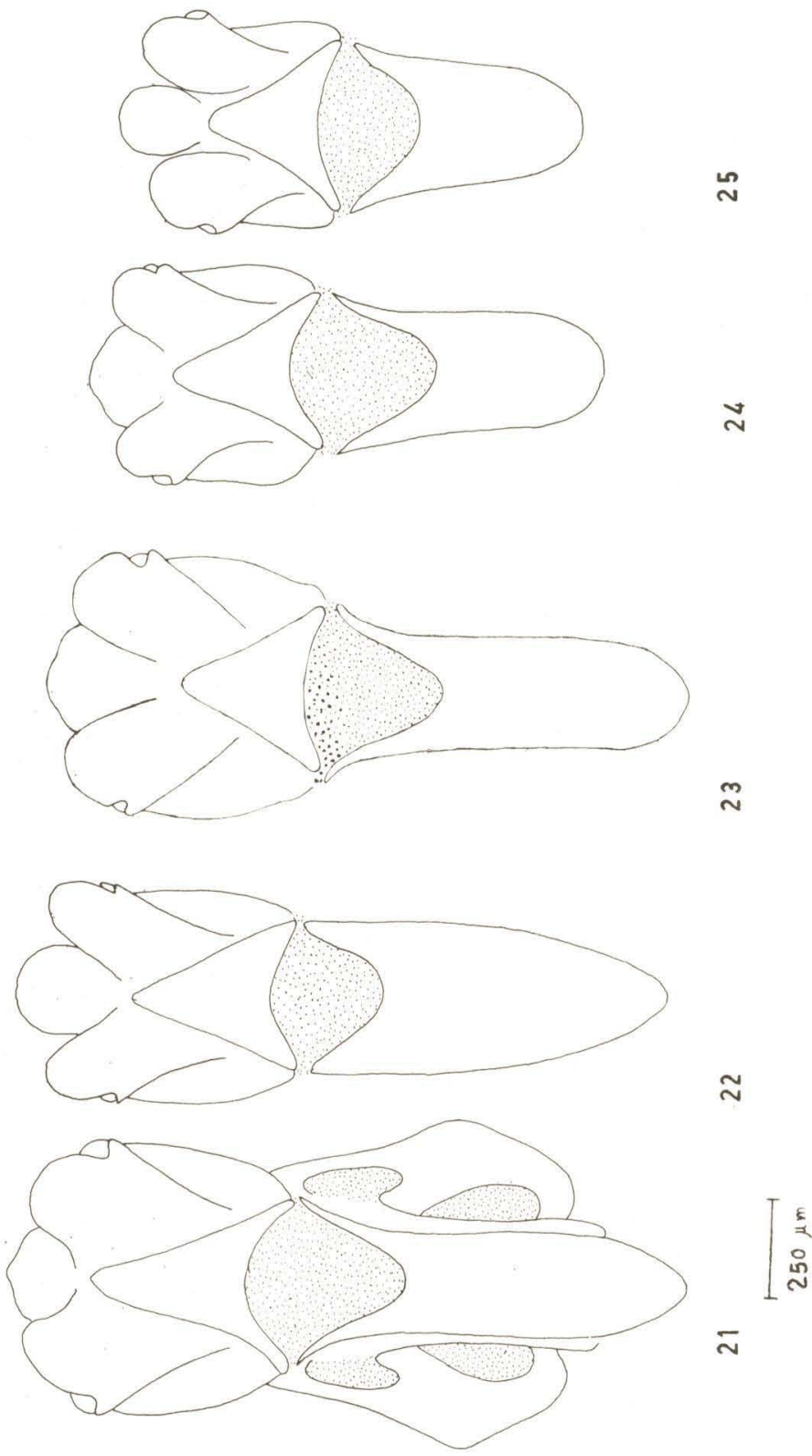

Plancha II - Metatórax, vista dorsal. Fig. 21: B. bahiensis, FAGR 0032. Fig. 22: B. fluminensis, holótipo. Fig. 23: B. myrapetrus, sp.n., holótipo. Fig. 24: B. occidentalis holótipo. Fig. 25: B. zikani, holótipo. 


\section{Revta bras. Zool.}
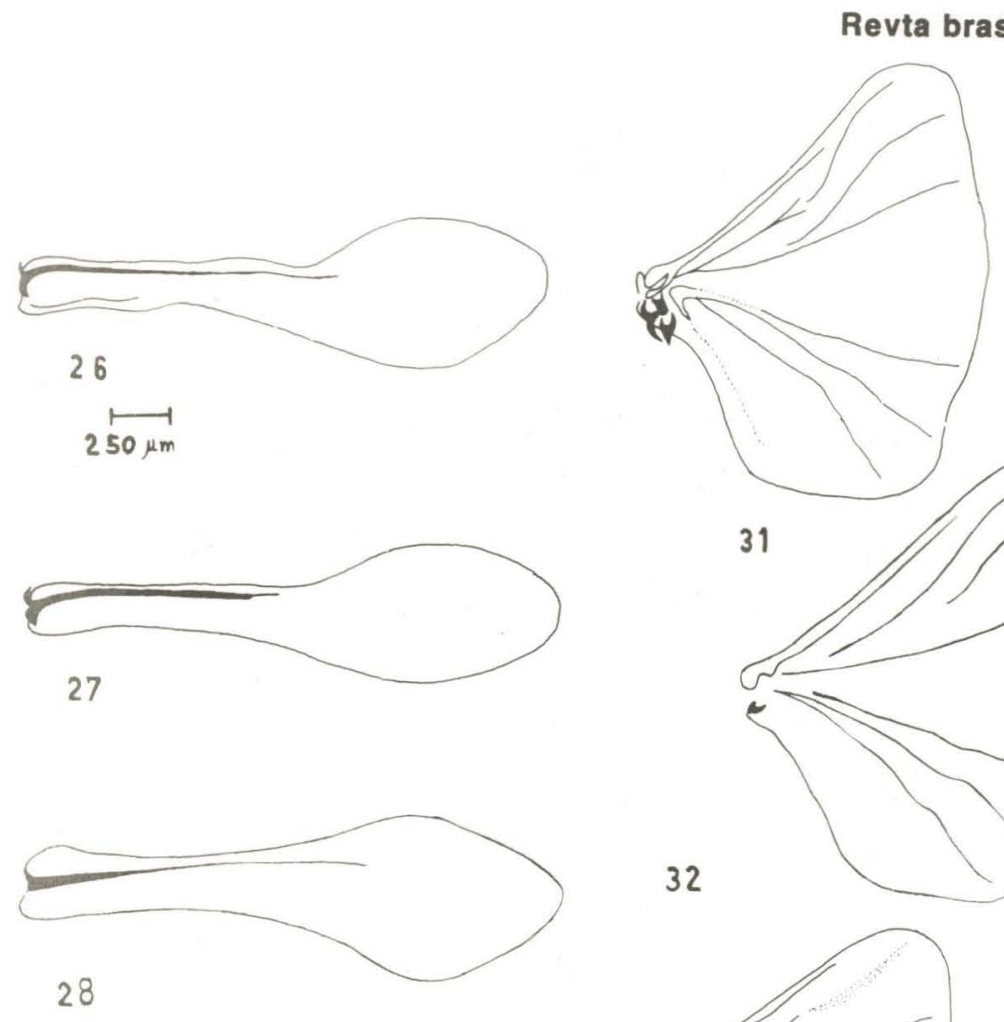
Vol. 5 (2), 1988

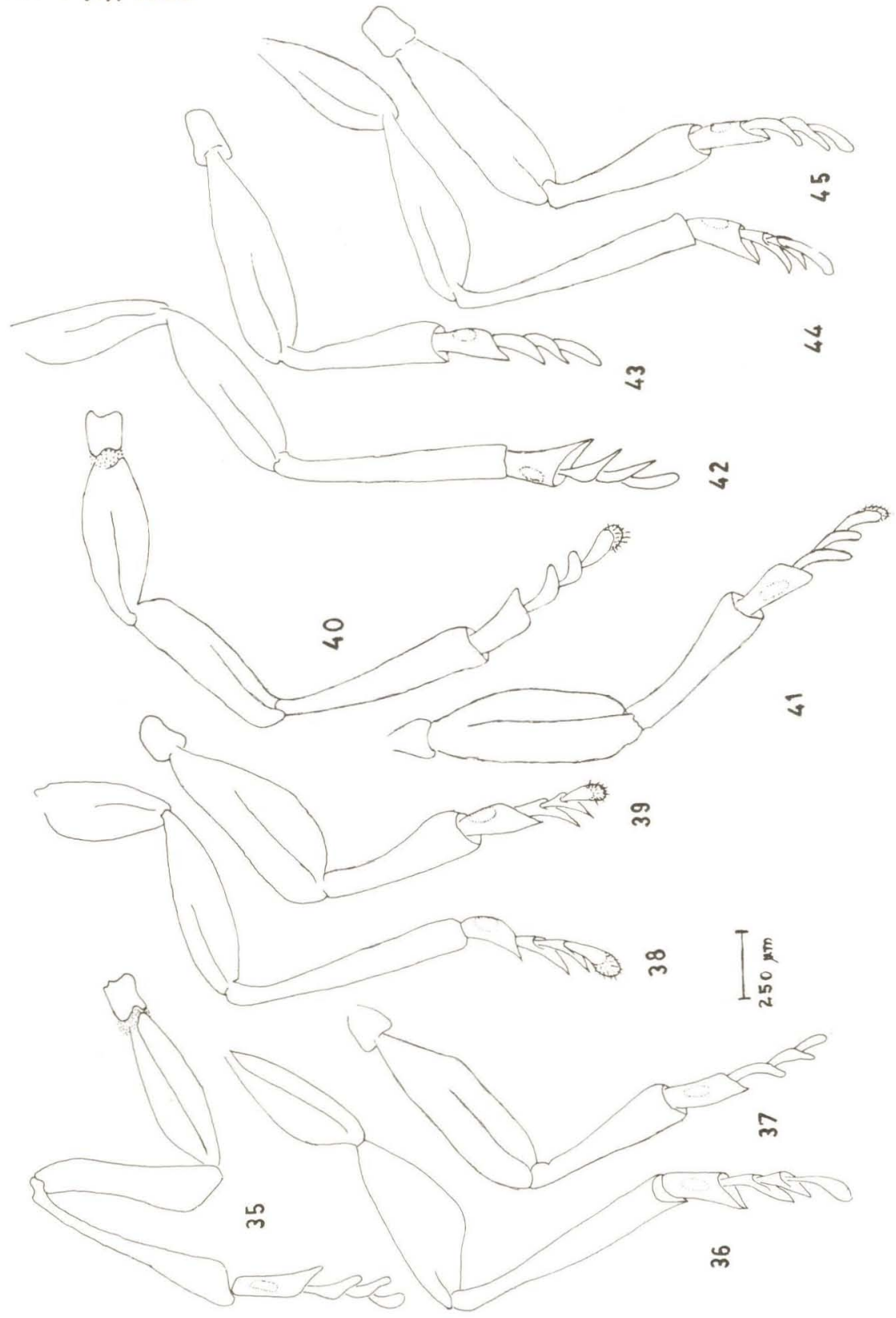

Plancha IV - Pernas, lado esquerdo, vista dorsal. Fig. 35 a $37:$ B. bahiensis, FAGR 0032. Fig. 38 e 39: B. fluminensis, holotipo. Fig. 40 e 41: B. myrapetrus, sp.n., holótipo. Fig. 42 e 43: B. occidentalis, holótipo. Fig. 44 e 45: B. zikani, holótipo. 
Revta bras. Zool.
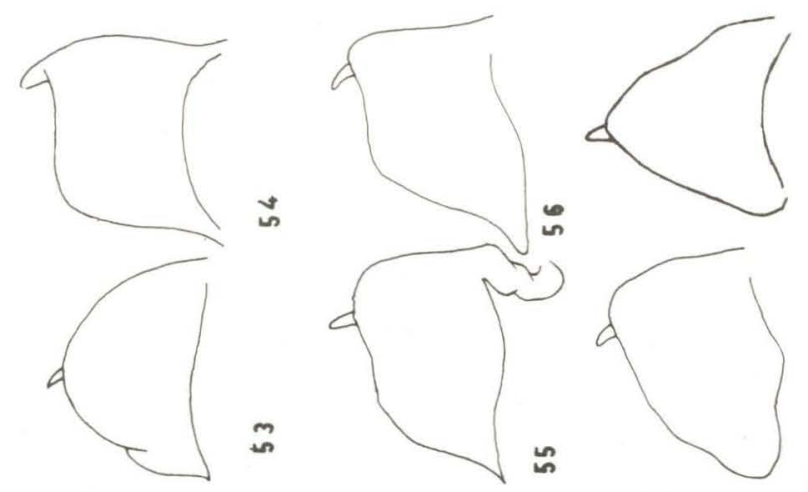

i
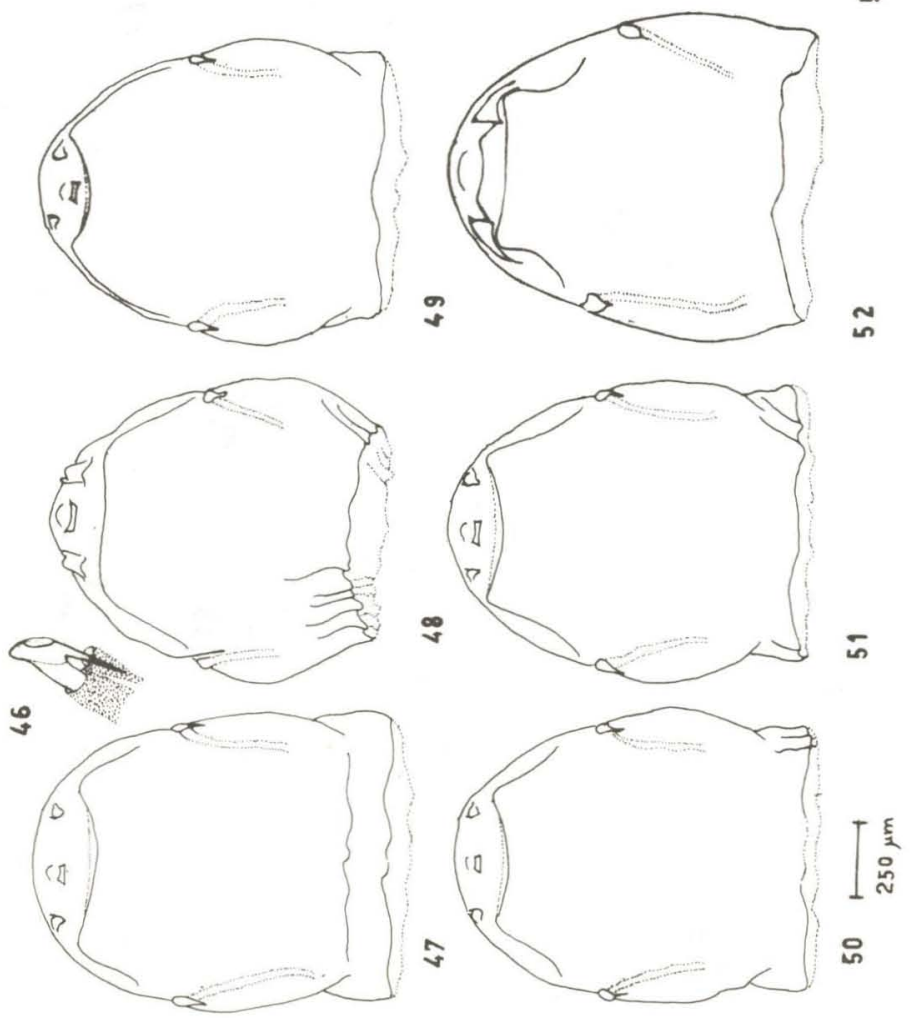

Plancha V - Cefalotórax e mandíbulas, vista ventral. Fig. 46, 47 e 53: $B$. acinctus, holótipo. Fig. 48 e 54: B. araujoi, holótipo. Fig. 49 e 55: B. bahiensis, holótipo. Fig. 50 e 56: B. brasiliensis, holótipo. Fig. 51 e 57: B. fluminensis, alótipo. Fig. 52 e 58: B. myrapetrus, sp.n., alótipo. 
Vol. 5 (2), 1988
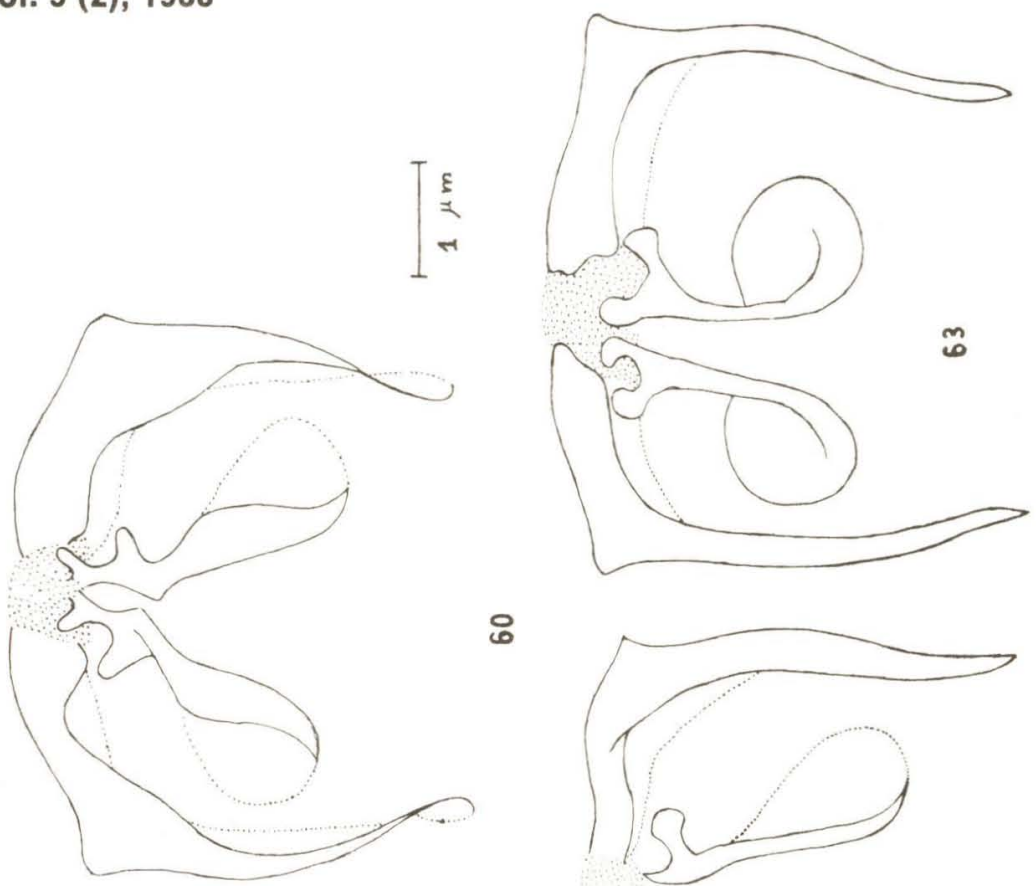

8
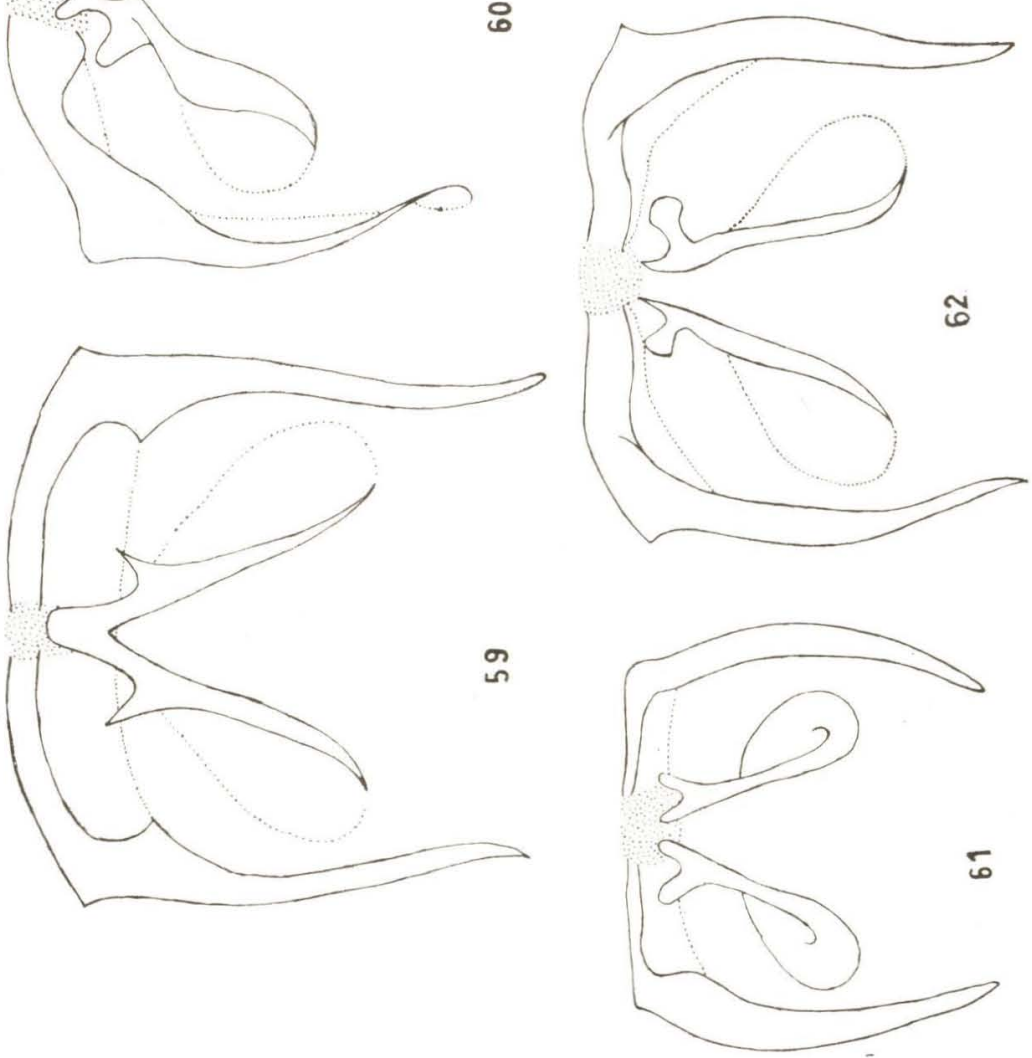

Plancha VI - Tentórios, vista ventral. Fig. 59: B. acinctus, parátipo. Fig. 60: B. araujoi, parátipo. Fig. 61: B. bahiensis, parátipo. Fig. 62: B. brasiliensis, parátipo. Fig. 63: B. fluminensis, parátipo. 